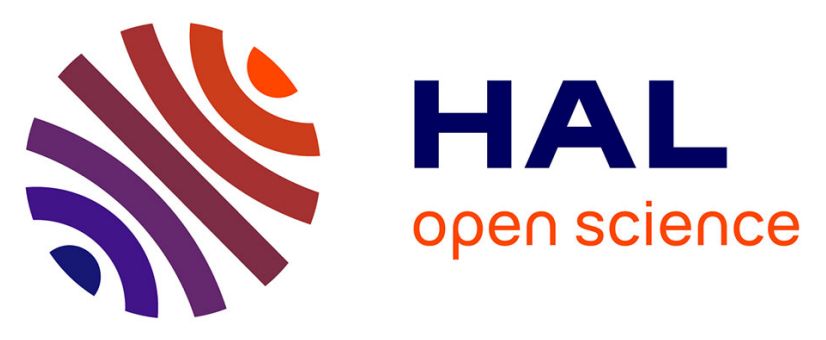

\title{
Abbreviated breast MRI combining FAST protocol and high temporal resolution (HTR) dynamic contrast enhanced (DCE) sequence
}

Audrey Milon, Saskia Vande Perre, Julie Poujol, Isabelle Trop, Edith

Kermarrec, Asma Bekhouche, Isabelle Thomassin-Naggara

\section{To cite this version:}

Audrey Milon, Saskia Vande Perre, Julie Poujol, Isabelle Trop, Edith Kermarrec, et al.. Abbreviated breast MRI combining FAST protocol and high temporal resolution (HTR) dynamic contrast enhanced (DCE) sequence. European Journal of Radiology, 2019, 117, pp.199 - 208. 10.1016/j.ejrad.2019.06.022 . hal-03487916

\section{HAL Id: hal-03487916 https://hal.science/hal-03487916}

Submitted on 20 Dec 2021

HAL is a multi-disciplinary open access archive for the deposit and dissemination of scientific research documents, whether they are published or not. The documents may come from teaching and research institutions in France or abroad, or from public or private research centers.
L'archive ouverte pluridisciplinaire HAL, est destinée au dépôt et à la diffusion de documents scientifiques de niveau recherche, publiés ou non, émanant des établissements d'enseignement et de recherche français ou étrangers, des laboratoires publics ou privés.

\section{(ㄷ)(1) $\$$}

Distributed under a Creative Commons Attribution - NonCommerciall 4.0 International 


\section{Abbreviated Breast MRI combining FAST protocol and High Temporal Resolution (HTR) Dynamic Contrast Enhanced (DCE) sequence}

Audrey Milon, $\mathrm{MD}^{1}$, Saskia Vandeperre, $\mathrm{MD}^{1}$, Julie Poujol, $\mathrm{PhD}^{1}$, Isabelle Trop $\mathrm{MD}^{3}$, Edith Kermarrec, $\mathrm{MD}^{1}$, Asma Bekhouche, $\mathrm{MD}^{1}$, Isabelle Thomassin-Naggara, $\mathrm{MD}, \mathrm{PhD}^{1,2}$

1-AP-HP, Hôpital Tenon, department of radiology 4 rue de la Chine, 75020, Paris, France

2-Sorbonne Universités, UPMC ISCD, Equipe medecine, Univ Paris 06, IUC, 75005, Paris, France

3- Centre hospitalier de Montréal, CHUM, department of radiology 3840 rue Saint-Urbain, Montréal,Canada

Short title: Breast MR abbreviated protocol

Type of manuscript: Original research

Key Words: Breast, MRI, FAST, high temporal resolution DCE sequence, cancer

\section{CONTRIBUTION :}

To evaluate the diagnostic performance of an abbreviated breast MRI protocol that reduces the acquisition time by almost half.

\section{Correspondence:}

Audrey Milon

Service de Radiologie,

Hôpital Tenon, 4 rue de la Chine,

75020, Paris, France

Tel.: +33156017830/+33676312083

Fax: +33156016402

e-mail: audrey.milon.am@gmail.com 


\section{ABSTRACT}

PURPOSE: We evaluated the diagnostic value of a high temporal resolution (HTR) dynamic contrast enhanced (DCE) sequence oversampling the first minute after contrast injection, added to a FAST protocol to compose an abbreviated breast Magnetic Resonance Imaging (MRI) protocol.

MATERIALS AND METHODS: 120 women (mean age=55 years (28-88)) who underwent breast MRI between July 2016 and March 2017 and in whom an abnormal enhancing lesion was identified with subsequent pathological analysis (i.e., gold standard) (R1-Q3) (n=179: 69 benign, 7 borderline and 103 malignant lesions) were retrospectively and consecutively included. Two readers classified lesions according to the Breast Imaging-Reporting and Data System (BI-RADS) by reading: a FAST protocol (T1W, T2W, T1W-fat saturated 2min after injection) and then a FULL standard protocol (FAST +4 successive T1W-fat saturated sequence after injection). Independently they determined if lesions were visible and when (Time To Enhancement (TTE)) on the ultra-fast sequence. An Abbreviated protocol was then built using data from the HTR-DCE sequence added to the FAST protocol.

RESULTS: All lesions were visible with the FAST protocol. 171/179 (95.5\%) lesions were detected by reading the-HTR-DCE sequence alone. There was a higher number of cancers rated BI-RADS 3 (PPV of malignancy of 27.6\% (8/29) in FAST versus 18.7\% (3/16) FULL protocol). An early enhancement on the HTR-DCE sequence (TTE<31s) was associated with malignancy with an OR 5.6 (CI 95\%: 3.3-20.4) ( $p<0.0001)$. Adding a TTE<31s to FAST analysis (AUROC $=0.826$ ) significantly improved lesion characterization with a diagnostic gain of $10.6 \%(19 / 179)$ lesions correctly reclassified $(p=0.0034)$ compared to the FAST protocol; with shorter acquisition time ( 7 min 48 s versus $13 \min 54 \mathrm{~s})$. 
CONCLUSION: Adding an HTR-DCE sequence to a FAST protocol increases diagnostic performance reaching that of the FULL standard protocol while reducing acquisition time. 


\section{INTRODUCTION}

Dynamic Contrast Enhanced (DCE) Magnetic Resonance Imaging (MRI) is an advanced imaging technique used to diagnose breast cancer with a reported sensitivity of $95 \%-99 \%$ and specificity values of $72 \%$ in meta-analyses (1). However, breast MRI is a complex time-consuming examination not only for the acquisition time (20 min on average) but also for the reading time (review of up to 2500 images) (1). Since 2014, new breast MRI protocols, called FAST protocols, have been developed characterized by only one acquisition after contrast associated—or not—with $\mathrm{T} 2 \mathrm{~W}$ and $\mathrm{T} 1 \mathrm{~W}$ morphological sequences acquired before injection. Following the landmark paper published by Kuhl et al. (2), many studies have demonstrated that FAST protocols have a similar sensitivity compared to conventional MRI protocols to detect breast cancer (3-14) both in women at high risk (3) and in the more general population of women referred for breast MRI (15). Nevertheless, the realization of conventional enhancement curves is not possible with these FAST protocols although using dynamic information has been demonstrated to improve breast MRI specificity (16).

More recently, Mann et al. described new dynamic characteristics of breast lesions using a high-temporal resolution (HTR) dynamic contrast enhanced (HTR-DCE) sequence oversampling the first minute after contrast injection, and reported a correlation between the slope of the time intensity curve during the first minute and lesion malignancy (9). A preliminary study using TRICKS acquisition (Time Resolved Imaging of Contrast KineticS, General Electric) further showed that malignant tumors are more often detected than benign lesions during the first 2 min after injection, significantly decreasing the number of false positives (8). However, a TRICKS sequence can generate false negatives, especially in the upper outer quadrant, mostly because of a decreased signal-to-noise ratio and a low spatial resolution. Moreover, in comparison with TRICKS sequence already used as HTR-DCE in 
breast MRI (8), time intensity curves can be calculated with the new HTR-DCE MRI sequence.

The main specific feature obtained on HTR-DCE sequences is based on the characteristics of invasive carcinomas and high-grade ductal carcinoma in situ (DCIS) that characteristically demonstrate fast initial uptake of contrast (within $90 \mathrm{sec}$ ) after contrast administration $(6,17-19)$.

Our objective was to compare a FAST protocol to the standard FULL protocol; and then to test the diagnostic performance of an additional HTR-DCE sequence oversampling the first minute after contrast administration (Abbreviated protocol) to improve lesion classification while decreasing acquisition time. 


\section{MATERIAL AND METHODS}

Our institutional review board approved the study and granted a waiver for informed consent.

\section{Patient Population}

Between July 2016 and March 2017, our MRI database was retrospectively queried to identify all women who had undergone breast MRI (n=520). Four hundred patients were excluded for the following reasons: negative exams ( $n=364)$, exams performed to guide an MRI procedure $(n=20)$; no contrast administration $(n=6)$, no HTR-DCE sequence $(n=5)$, biopsy-proven lesions without enhancement on MRI (n=3), problem related to the Picture Archiving and Communication System (PACS) $(n=1)$, lesions of uncertain nature in women who underwent MRI for breast cancer follow-up with neoadjuvant chemotherapy $(n=1)$.

The final population consisted of 120 women (mean age: 56 years, range 28-88) with 179 lesions (Figure 1), of whom 63\% were menopausal (75/120). Of these, 18/120 (15\%) were at high risk; 29/120 (24\%) had been treated for breast cancer; 32/120 (27\%) reported a family history of breast cancer; 30/120 (25\%) had a personal history of benign breast biopsy; and 11/120 (9\%) had no previous breast cancer history. Breast MRI indications were breast cancer staging $(75 / 120(62 \%))$, problem solving after inconclusive mammography or ultrasound (US) assessment (24/120 (20\%)), high-risk screening (9/120 (7.5\%)), monitoring of seemingly benign lesions (Breast Imaging-Reporting and Data System (BI-RADS) 3) $(4 / 120(3.3 \%))$, nipple discharge assessment $(3 / 120(2.5 \%))$, search for primary cancer in women with a metastatic axillary lymphadenopathy $(2 / 120(1.7 \%))$, before neoadjuvant chemotherapy $(2 / 120(1.7 \%))$, before prophylactic mastectomy $(1 / 120(0.8 \%))$.

\section{Reference standard}


Biopsy was performed for suspicious lesions (BI-RADS 4-5) or for BIRADS 3 lesions depending on the context. For MRI-enhancing lesions with a sonographic correlation, biopsy was performed with an automatic 14-gauge core needle (73\% of lesions (130/179)), or with a 7 to 10 -gauge vacuum-assisted core needle either under stereotactic guidance in $12 \%$ (22/179), under MRI guidance in 10\% (18/179) or under US guidance in 2\% (4/179). Three lesions (3/179) (1.7\%) had a fine needle aspiration. One lesion (1/179) $(0.5 \%)$ was investigated directly by surgical biopsy guided radiologically. Information on how the biopsy was performed was unavailable for one $(0.5 \%)$. Biopsies were performed either before or after MRI: 56.4\% (101/179) after the MRI scan within a maximum period of 4 months and $43.6 \%$ (78/179) prior to MRI scan. Pathological analysis was performed with reference standards determined based on histopathological findings of percutaneous biopsies for benign lesions ( $n=69)$, or on surgery results for high-risk lesions $(n=7)$ or malignant tumors $(n=103)$ including 18 pure DCIS. Final excision histology results are summarized in Table 1.

\section{MRI acquisition}

Patients were imaged in the prone position on a 1.5 T GE Optima MR450w GEM system using a dedicated 8-channel breast array coil (GE, Milwaukee, USA). The acquisition protocol is presented in Figure 2, and sequence parameters are detailed in Supplemental material 2. T1 and T2-weighted non-fat-saturated axial sequences were acquired before contrast administration. Dynamic contrast-enhanced T1-weighted fat-saturated gradient-echo sequences (VIBRANT, GE) were acquired before and four times after a bolus injection of Gadolinium chelate (Dotarem $0.5 \mathrm{mmol} / \mathrm{mL}$; Guerbet, Villepinte) $\left(0.2 \mathrm{~mL} \cdot \mathrm{kg}^{-1}\right.$ body weight). The bolus injections were infused via a power injector (Mallinckrodt, Guerbet, Villepinte) at a rate of $2 \mathrm{ml} . \mathrm{s}^{-1}$, followed by a $20 \mathrm{~mL}$ saline flush. The HTR-DCE sequence (DISCO: 
Differential Subsampling with Cartesian Ordering) was performed before the first phase of the T1 VIBRANT sequence. DISCO sequence acquisition began simultaneously with the contrast injection; 11 temporal DISCO ranks were thus acquired for $1 \mathrm{~min} 18 \mathrm{sec}$ ( $7.7 \mathrm{sec}$ per rank) in order to assess early lesion enhancement. The DISCO sequence is a T1W GradientEcho sequence undersampling k-space that enables higher temporal resolution than a standard T1W VIBRANT sequence. Total acquisition time for the Abbreviated protocol (including T2W, T1W, DISCO and first acquisition of T1W VIBRANT) was 7 min $48 \mathrm{sec}$ whereas total acquisition time for the FULL protocol including all time acquisition VIBRANT sequences was $13 \mathrm{~min} 54 \mathrm{sec}$. Post-processing consisted of subtracting images, building Maximum Intensity Projection (MIP) reconstructions and parametric maps (Positive Enhancement Integral - PEI and Maximum Slope of Increase - MSI) derived from the VIBRANT and DISCO sequences. All MR images were stored on a PACS and then reviewed on a dedicated separate workstation (AW server, GE healthcare, Milwaukee).

\section{Reading the protocols}

Two radiologists, blinded to the clinical data, indication and pathological results, with 6 and 2 years of experience in breast MRI (senior and junior reader, respectively) independently reviewed the images.

According to the BI-RADS classification, breast parenchymal density and background glandular enhancement were recorded.

\section{The FULL protocol}


The readers were asked to classify the lesions from the FULL protocol according to the MRI BI-RADS lexicon based on morphology and enhancement characteristics (obtained from curves type $1,2,3)$.

\section{The FAST protocol}

One month later, the readers were asked to read the FAST protocol (consisting of T2W, T1W and the first T1fat-saturated VIBRANT after contrast injection). They were first asked independently to determine if any lesions were detected and then to characterize and classify enhanced lesions according to the BI-RADS classification and blinded from any dynamic enhancement parameters from dynamic curves.

\section{The Abbreviated protocol (FAST + HTR-DCE)}

The readers were first asked to state if a lesion was visible on the HTR-DCE (= DISCO) sequence and to determine in which of the 11 ranks the lesion first became visible.

For semi-quantitative analysis, they were then asked independently to draw two 2Dregion-of-interest (ROI) on the HTR-DCE (DISCO) sequence for each lesion detected: a whole-lesion-ROI and a hotspot-ROI. If the trajectory of the biopsy was visible within the lesion, or if a necrotic or cystic part was identified, care was taken to draw the 2D ROI on a slice that did not reveal any cystic or post-biopsy changes. The hotspot-ROI was selected in the region with the most intense enhancement on the parametric PEI map derived from the HTR-DCE sequence. Enhancement curves were extracted from AW server software by a research engineer (GE, Milwaukee, USA). The following parameters were extracted directly from the curves: Enhancement Integral (EI (\%), Maximum Slope of Increase (MSI (\%/sec)), Maximum of enhancement (Rmax (\%)), Timing of Maximum of enhancement (RmaxTiming $(\mathrm{sec}))$ and Wash-in-rate $((\mathrm{WIR}(\% / \mathrm{sec})$. Then the curves were fitted using a Hill equation 


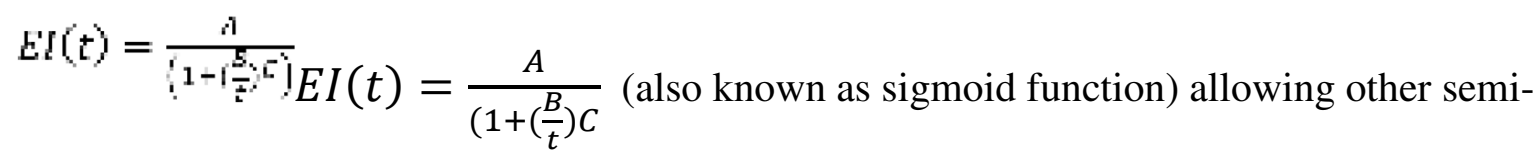
quantative parameter analysis as previously described (20) where A is the asymptotic enhancement amplitude (EA), B is the time of half rising (THR), and C is a power constant (Figure 3) (21) using Matlab Software (The MathWorks, Inc., Natick, Massachussets, United States). An analysis of heterogenetiy was also perfomed on the whole lesion ROI by extracting Standard Deviation (STD) of the values from the differents pixels in the lesion within the different enhancement ranks of the HTR-DCE sequence.

\section{Statistical analysis}

Analysis was performed on statistics software MedCalc (Ostend, Belgium), version 2018. Descriptive analysis was performed using a non-parametric Mann-Whitney test for noncontinuous variables. To determine whether "continuous values" could differentiate malignant from benign lesions, thresholds were determined by constructing a receiver operating characteristic (ROC) curve. We calculated odds ratios (OR) for predicting malignancy with $95 \%$ confidence intervals and p-values for each of the predictor variables for malignancy. The Results section is based on the senior reading. Quadratic $\kappa$ coefficients were calculated to assess the reproducibility for lesion characterization between the two protocols (FAST and Full protocol), according to morphological criteria. Quadratic $\kappa$ coefficients were calculated to assess interobserver agreements with a junior reader for enhancement rank determination on the HTR-DCE MRI sequences and for BI-RADS classification on the different reading protocols. Univariate analysis was used to calculate the OR for each of the predictor variables for malignancy. Then step-by-step logistic regression analysis was performed to determine which criteria were significantly associated with malignancy. A ROC curve analysis was 
performed to compare the results of interpretations based on the FULL (gold standard) protocol versus the Abbreviated protocol using De Long et al.'s method (22).

We determined the diagnostic performances of each protocol calculating positive predictive values and positive likelihood ratios and then diagnostic gain using Mac Nemar test.

A $p$ value of less than 0.05 was considered to indicate a statistically significant difference. 


\section{RESULTS}

\section{Population}

Breast density was evaluated as type A in 8.3\% (10/120), type B in 45\% (54/120), type $\mathrm{C}$ in $34.2 \%(41 / 120)$ and type $\mathrm{D}$ in $10 \%(12 / 120)$ of patients. $2.5 \%(3 / 120)$ had a bilateral mastectomy with breast reconstruction. Background glandular enhancement was categorized as minimal (type 1) in 77.5\% (93/120), mild (type 2) in $8.3 \%(10 / 120)$, moderate (type 3$)$ in $9.2 \%(11 / 120)$ and intense (type 4$)$ in $5 \%(6 / 120)$ of patients.

\section{Lesion description}

The lesion was a mass in $70 \%(125 / 179)$ of patients, a non-mass enhancement (NME) in $27.3 \%(49 / 179)$ and a focus in $2.7 \%(5 / 179)$. The average lesion size was $18 \mathrm{~mm}(3-85$ $\mathrm{mm})$ :. $<10 \mathrm{~mm}$ in 45/179 (25.1\%); from 10 to $20 \mathrm{~mm}$ in 49/179 (27.4\%), and >20 $\mathrm{mm}$ in 85/179 (47.5\%). For masses, the most discriminant morphological criteria to distinguish benign from malignant lesions were the shape and margin with an OR of 7.7 (CI 95\%: 3.318.2) and 8.2 (CI 95\%: 3.3-20.4), respectively (Table 2). For NME, suspicious internal enhancement was the most effective morphological criterion to distinguish benign from malignant lesions with an OR of 5.2 (CI 95\% 1.44-18.71); $p=0.0116$. A high concordance for most of the morphological criteria was found between the Full and FAST protocol analysis with $\kappa$ values between $0.70-0.95$ (Table 2).

\section{BI-RADS performance on FULL and FAST protocol readings}

With the FULL protocol, all lesions were visible and positive predictive values of BI-RADS $3,4 \mathrm{a}, 4 \mathrm{~b}, 4 \mathrm{c}$ and 5 were $18.7 \%(3 / 16), 21.2 \%(7 / 33), 37.5 \%(12 / 32), 69.8 \%(30 / 43)$ and 92.7\% (51/55), respectively, with an AUROC of 0.834 (Table 3). All the cancers were detected with the FAST protocol but diagnostic performance was lower (AUROC: 0.802) 
compared to the FULL protocol (AUROC: 0.834$)(p<0.01)$ and there were more cancers rated BI-RADS 3 (PPV of malignancy 27.6\% (8/29) in FAST versus 18.7\% (3/16) FULL protocol), probably due to the the lack of enhancement curve study.

\section{HTR-DCE sequence analysis}

171/179 (95.5\%) lesions were visible on the HTR-DCE sequence only: the eight (4.5\%) lesions which were not identified consisted of 5/76 (3.9\%) benign lesions and 3/103 $(2.9 \%)$ breast cancers. The three undetected cancers were two small invasive ductal carcinomas (IDC) (of 6 and $7 \mathrm{~mm}$ ), and one papillary carcinoma that appeared as an NME (of $7 \mathrm{~mm}$ ). The five unenhanced benign lesions consisted of one adenofibroma and four fibrocystic changes. All lesions visible on the HTR-DCE sequence enhanced within the first seven ranks (less than 1 min after injection).

Most of the cancers $(84 \%, 87 / 103)$ enhanced within the first four ranks (i.e., $31 \mathrm{sec}$ after injection (7.7 sec x 4). Building a ROC curve to predict malignancy, an early enhancement $\leq 4$ (rank 1-2-3-4) was the best cut off between sensitivity and specificity versus late enhancement (rank 5-6-7-8-9-10-11). Malignant lesions were 5.6 times more likely to be associated with early enhancement (within the first four ranks, with a mean Time To Enhancement (TTE) $<31 \mathrm{sec}$ ), as opposed to delayed (after the fourth rank) with an OR = 5.6 (CI 95\%: 3.3 - 20.4; $p<0.0001$ ) (Figure 4). There was a significant but low negative correlation $(\mathrm{r}=-0.3, p=0.002)$ between lesion size and the first rank where the lesion was detected (Figure 5). However, independently from size, an earlier first rank of lesion detection was correlated with malignancy.

All semi-quantitative parameters were significantly different between benign and malignant lesions (except Rmax timing) independently from hotspot- or whole-lesion- ROI. 
Malignant lesions displayed a higher EI, a higher EA, a shorter THR, a steeper MS, a higher MSI, a higher WIR, and a higher Rmax (Table 4).

Malignant lesions were more heterogeneous than benign lesions on the HTR-DCE sequence with a higher STD irrespective of the rank $(p<0.0001)$. The results were also significant in the subgroup of lesions not biopsied before MRI $(n=101)(p<0.001)$. The best AUROC to distinguish benign from malignant lesions was obtained at rank 5 (AUROC

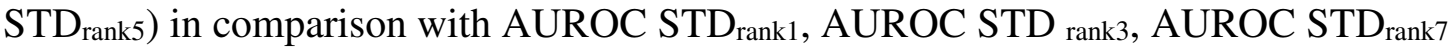
AUROC STD rank9 $_{\text {and AUROC STD }}$ rank11 (Table 5). For each semi-quantitative parameter we also compared the ROC curve (AUROC) between hotspot- and whole-lesion-ROI. As no significant difference was found between hotspot- and whole-lesion-ROI for any of the semiquantitative parameters (EI, EA, MS, THR, Rmax) and as lesion inhomogeneity parameters can be extracted only from the whole-lesion-ROI, we calculated the cut off from the ROC curve for each parameter extracted from whole-lesion ROI analysis (Table 6).

Finally, at multivariate analysis including all significant features from HTR-DCE sequence analysis (TTE <31 s or rank 1-2-3-4, EA, EI, THR, MS, MSI, RMax, WIR and $\mathrm{STD}_{\text {rank5 }}$ ), only TTE $<31 \mathrm{sec}$ was significantly associated with malignancy $(p<0.0001 \mathrm{OR}=$ 3.9). The readers thus reclassified BI-RADS 3, BI-RADS 4a, BI-RADS $4 \mathrm{~b}$ using the data from the HTR-DCE sequence (i.e., early enhancement (TTE <31 sec or rank 1-2-3-4) as follows: BI-RADS 3 lesions with a suspicious early enhancement (TTE $<31 \mathrm{sec}$ ) were upgraded as BI-RADS 4a lesions; and BI-RADS 4a and 4b lesions with a non-suspicious late enhancement (TTE > $31 \mathrm{sec}$ ) were downgraded as BI-RADS 3 lesions (Figure 6). We did not reclassify BI-RADS 4c or BI-RADS 5 lesions because a suspicious morphology warrants biopsy regardless of enhancement features. Predictive positive values as well as positive likelihood ratio for each BI-RADS category determined for each protocol are summarized in 
Table 3 and percentage of malignant lesions for each protocol reading represented in Figure 7.

The Abbreviated protocol (combining FAST and HTR-DCE sequence data) had better diagnostic performance $(\mathrm{AUROC}=0.826)$ compared to the FAST protocol $(\mathrm{AUROC}=0.802)$ $(p<0.01)$ and a non-significantly different performance compared to the FULL protocol (AUROC=0.834). The Abbreviated protocol could have avoided unnecessary biopsies for $8.9 \%$ of the lesions $(16 / 179)$ rated BI-RADS $4 \mathrm{a}$ and $4 \mathrm{~b}$ with the FAST protocol and confirmed benign ( $p=0.0139)$, and for $10.6 \%$ (19/179) of the lesions incorrectly rated with the FULL protocol ( $p=0.0034)$ (Figure 8) (Table 7). False negative-cancers rated BI-RADS 3with our Abbreviated protocol were two IDC, one papillary carcinoma and two DCIS. The two IDC and the papillary carcinoma were the same lesions that were missed with the FULL protocol. The two additional false negatives that occurred with our Abbreviated protocol were two high-grade DCIS lesions: one was diagnosed upon surgical excision, and the other was already known from a screening mammography and a subsequent vacuum-assisted stereotactic core-needle biopsy performed before the MRI scan. Breast MRI was done to rule out multifocal disease and to determine if a conservative treatment was still possible. The lesion was almost not visible because of post-biopsy hematoma, explaining why no enhancement was visible on the HTR-DCE sequence. There were 8/179 (4.5\%) false positive -benign BI-RADS 3 lesions upgraded because of early enhancement consisting of infracentimetric foci $(\mathrm{n}=1)$ and mass $(\mathrm{n}=7$; size $=8-17 \mathrm{~mm})$, and an $11 \mathrm{~mm}$ cyst $(\mathrm{n}=1)$.

\section{Reproducibility of FAST and HTR-DCE results between the senior and junior readers} Inter-reader agreement of BI-RADS classification for the FAST protocol was excellent with a $\kappa$ value equal to $0.801(0.715-0.887)$. 
Inter-reader agreement to determine the first rank of the HTR-DCE-sequence to detect the lesion was good with a $\kappa$ value of $0.651(0.535-0.768)$

Inter-reader agreement for BI-RADS performance of the Abbreviated protocol was excellent with a $\kappa$ value of $0.889(0.840-0.938)$ 


\section{DISCUSSION}

Our study demonstrates that adding the HTR-DCE sequence to a FAST protocol consisting of T2W, T1W and the first T1fat-saturated VIBRANT after contrast injection, improves the diagnostic value of the BI-RADS classification for breast cancer to reach values obtained from a standard protocol with a markedly reduced acquisition time $(7 \mathrm{~min} 48 \mathrm{sec}$ versus $13 \min 54 \mathrm{~s}$ ). We also demonstrate that a lesion that enhances within the first 31 seconds after injection has 5.6 times more risk to be a cancer.

Our results are in line with those published by Mus et al. on TWIST acquisition. In their study, malignant tumors had a time-of-arrival (TOA) (delay between the aorta and onset of lesion enhancement) $12.96 \mathrm{sec}$ shorter compared to benign tumors (10). In another study, Oldrini et al. demonstrated that the visibility of breast lesions on TRICKS acquisition oversampling the first minute after injection was correlated with malignancy, leading to a significant reduction in the number of false positives (8). These dynamic characteristics may be related to the presence of poorly formed and fragile neoangiogenic vessels in breast cancers. In addition, microvessels of malignant tumors lack a muscular coat and are highly permeable (20). Use of a HTR sequence provides detailed information regarding the initial part of the time intensity curve including MSI, THR and EA. These semi-quantitative parameters are not only correlated with the number of microvessels in breast cancers (positive correlation with immunohistochemical CD31) $(23,24)$ but also reflect parietal immaturity (20). We chose to use a $7.7 \mathrm{sec}$ temporal resolution for our HTR-DCE sequence based on preliminary studies where the sensitivity of the dynamic sequence with a higher temporal resolution was decreased because of low spatial resolution (8). A 7.7 sec HTR-DCE sequence allows sufficient sampling to build a dynamic curve. Our temporal resolution was high but 
could not determine TOA because of imprecise aortic enhancement within the first two ranks due to our temporal resolution. Our study demonstrates that HTRE-DCE (DISCO) sequence is accurate in identifying these physiopathological characteristics, with higher EA, shorter THR and steeper MS in breast cancers compared to benign tumors. Until now, breast MRI has been based on low resolution dynamic sequences with only permeability features being available to differentiate benign from malignant tumors including washout criteria, which is a specific (but not very sensitive) sign of malignancy. Indeed, $87 \%$ of lesions with wash-out are malignant, but the wash-out phenomenon is found in only $57 \%$ of cancers (16). Using HTRDCE acquisition, Mann et al. compared the MS of relative enhancement obtained from the TWIST acquisition to the information obtained on time-curve types from the regular dynamic sequence as defined in the BI-RADS lexicon (9). In a population of 160 women with 199 enhancing abnormalities (95 benign and 104 malignant), they demonstrated that the MS from the TWIST sequence resulted in discrimination of benign and malignant lesions with high accuracy (9), as we also observed in our study. However, our results show that the best semiquantitative paramater is the THR (AUROC 0.712) which performs better than other criteria, including MS (AUROC 0.650) or MSI (AUROC 0.702). These semi-quantitative results are in line with descriptive results that show that TTE or TOA are highly accurate to identify breast cancers (10).

In addition, the ultrafast sequence can identify the well-known heterogeneity described on standard dynamic sequences in breast cancers (25). Our results underline that malignant lesions are more heterogeneous than benign lesions and this holds true on HTR-DCE sequences with a higher STD regardless of the rank $(p<0.0001)$.

Our study demonstrated that HTR-DCE sequences, which provide good but suboptimal spatial resolution, cannot be used alone as three breast cancers were missed (two 
IDC (of 6 and 7mm) and one papillary carcinoma (of $7 \mathrm{~mm}$ ). Most publications of abbreviated protocols have evaluated dynamic sequences with K-space undersampling (TWIST, TRICKS, DISCO sequence). Such acquisition acceleration techniques involve the concept of view sharing based on an undersampling of the periphery of K-space that allows a higher temporal resolution (by rapid acquisition of multiple ranks during infusion of the contrast bolus), although lower spatial resolution can limit morphological lesion analysis (28). Even if DISCO sequences have a better spatial resolution than previously published HTRDCE protocols (as TRICKS for example), the combination with the FAST protocol is useful to maintain the very high spatial resolution obtained with conventional post-contrast 3D sequences and detect very small lesions. The eight lesions missed by the HTR-DCE MRI sequences (DISCO) corresponded to five unenhanced benign lesions and three invasive cancers smaller than $1 \mathrm{~cm}$.

Several studies show that low-grade IDC, invasive lobular carcinoma (ILC) and DCIS have a later enhancement compared to other invasive carcinomas $(26,27)$ and this may constitute a limitation for the development of an abbreviated protocol. One way to avoid this limitation is to include morphological criteria in this analysis. Indeed, most late-enhancing ILC are NME with architectural distortion that may easily be recognized on conventional T1W, T2W and $1^{\text {st }}$ injected T1W VIBRANT sequence included in the FAST protocol. Spatial resolution of our HTR-DCE sequence was relatively low and did not allow an optimal morphological analysis; explaining why we included a conventional low temporal but high spatial resolution T1W sequence. In our study, NME with architectural distortion or masses with irregular shape and spiculated margins were rated BI-RADS $4 \mathrm{c}$ or 5 with both the FAST and the FULL protocol, possibly due to their morphological characteristics reflecting a slow neoplastic process with few neoangiogenic characteristics. Our study demonstrates a good 
concordance on the analysis of morphological criteria between the FAST and FULL standard protocol (Kappa >0.7) for margins and mass shape.

Based on multivariate analysis, we suggest that the information from the HTR-DCE sequence (TTE) be added to the BI-RADS assessment of lesions classified as BI-RADS 3, 4a and $4 \mathrm{~b}$ by the FAST protocol (Supplemental material 2). We decided to use wash-in kinetics to downgrade BI-RADS $4 \mathrm{~b}$ lesions as most cancers with a TTE $>31$ sec were rated BI-RADS $4 \mathrm{c}$ or $5(75 \%, 12 / 16))$. Prospective validation studies are ongoing in two external centers. The semi-quantitative criteria evaluated did not significantly improve the diagnostic performance we achieved using simple and reproducible TTE criteria. Our Abbreviated protocol combining the FAST protocol and HTR-DCE sequences obtained a better performance than the FAST protocol alone, especially avoiding unnecessary breast biopsies of the downgraded BI-RADS 4a and $4 \mathrm{~b}$ lesions to BI-RADS 3. We did not modify any BI-RADS 4c and 5 lesion classification because, as previously discussed, dynamic features should rule out a suspicion of malignancy based on morphological criteria. Cancers wrongly downgraded based on the Abbreviated protocol compared to the FULL protocol were two high-grade DCIS downgraded BIRADS 3 because of late enhancement; these two false negatives were correctly diagnosed on mammography (microcalcifications), which illustrates the importance of different modality combinations.

Our study presents several limitations. First, the prevalence of cancer was higher than in previous studies (57.5\% of lesions), probably due to a combination of the following elements: a high number of MRI exams were performed preoperatively before oncoplasty and to assess difficult cases referred to our academic center for breast disease. We thus calculated a positive likelihood ratio for malignancy, which was not influenced by the high prevalence in contrast with positive predictive values. Second, due to the design of the study, all lesions 
were sampled by percutaneous biopsy and no BI-RADS 1 or 2 were present in our study. This may explain the very low specificity of the different protocols relative to the very low number or true negatives (only represented by BI-RADS 3 lesions). Third, reading time was not recorded in our study because a second BI-RADS classification was performed using the TTE. Finally, our cut-off malignancy parameter (TTE $<31 \mathrm{sec}$ ) was retrospectively determined in our study without any validation data set. Thus, further prospective studies are necessary to validate this criterion.

In conclusion, an abbreviated breast MRI protocol combining a FAST protocol and HTR-DCE acquisition is an effective diagnostic approach that could lead to better availability of MRI by increased throughput while reducing the costs of a breast MRI scan. An HTR-DCE sequence provides information on early enhancement characteristics (TTE $<31 \mathrm{sec}$ ), which is a useful parameter for lesion characterization, reducing unnecessary biopsies. 


\section{REFERENCES}

1. Peters NH, Borel Rinkes IH, Zuithoff NP, Mali WP, Moons KG, Peeters PH. Metaanalysis of MR imaging in the diagnosis of breast lesions. Radiology. 2008;246(1):116124.

2. Kuhl CK, Schrading S, Strobel K, Schild HH, Hilgers R-D, Bieling HB. Abbreviated breast magnetic resonance imaging (MRI): first postcontrast subtracted images and maximum-intensity projection - a novel approach to breast cancer screening with MRI. Journal of Clinical Oncology. 2014;32(22):2304-2310.

3. Harvey SC, Di Carlo PA, Lee B, Obadina E, Sippo D, Mullen L. An abbreviated protocol for high-risk screening breast MRI saves time and resources. Journal of the American College of Radiology. 2016;13(4):374-380.

4. Strahle DA, Pathak DR, Sierra A, Saha S, Strahle C, Devisetty K. Systematic development of an abbreviated protocol for screening breast magnetic resonance imaging. Breast cancer research and treatment. 2017;162(2):283-295.

5. Mango VL, Morris EA, Dershaw DD, Abramson A, Fry C, Moskowitz CS, et al. Abbreviated protocol for breast MRI: are multiple sequences needed for cancer detection? European journal of radiology. 2015;84(1):65-70.

6. Heacock L, Melsaether AN, Heller SL, Gao Y, Pysarenko KM, Babb JS, et al. Evaluation of a known breast cancer using an abbreviated breast MRI protocol: correlation of imaging characteristics and pathology with lesion detection and conspicuity. European journal of radiology. 2016;85(4):815-823.

7. Moschetta M, Telegrafo M, Rella L, Stabile Ianora AA, Angelelli G. Abbreviated Combined MR Protocol: A New Faster Strategy for Characterizing Breast Lesions. Clin Breast Cancer. 2016 Jun;16(3):207-11.

8. Oldrini G, Fedida B, Poujol J, Felblinger J, Trop I, Henrot P, et al. Abbreviated breast magnetic resonance protocol: Value of high-resolution temporal dynamic sequence to improve lesion characterization. European Journal of Radiology. 2017 Oct 1;95:177-85.

9. Mann RM, Mus RD, van Zelst J, Geppert C, Karssemeijer N, Platel B. A novel approach to contrast-enhanced breast magnetic resonance imaging for screening: highresolution ultrafast dynamic imaging. Investigative radiology. 2014;49(9):579-585.

10. Mus RD, Borelli C, Bult P, Weiland E, Karssemeijer N, Barentsz JO, et al. Time to enhancement derived from ultrafast breast MRI as a novel parameter to discriminate benign from malignant breast lesions. European Journal of Radiology. 2017;89:90-96. 11. Abe H, Mori N, Tsuchiya K, Schacht DV, Pineda FD, Jiang Y, et al. Kinetic analysis of benign and malignant breast lesions with ultrafast dynamic contrast-enhanced MRI: comparison with standard kinetic assessment. American Journal of Roentgenology. 2016;207(5):1159-1166.

12. Pineda FD, Medved M, Wang S, Fan X, Schacht DV, Sennett C, et al. Ultrafast Bilateral DCE-MRI of the Breast with Conventional Fourier Sampling. Academic Radiology. 2016 Sep;23(9):1137-44.

13. Jimenez JE, Strigel RM, Johnson KM, Henze Bancroft LC, Reeder SB, Block WF. Feasibility of high spatiotemporal resolution for an abbreviated 3D radial breast MRI protocol. Magnetic resonance in medicine. 2018; 
14. Vreemann S, Rodriguez-Ruiz A, Nickel D, Heacock L, Appelman L, van Zelst J, et al. Compressed Sensing for Breast MRI: Resolving the Trade-Off Between Spatial and Temporal Resolution. Investigative radiology. 2017;52(10):574-582.

15. Moschetta M, Telegrafo M, Rella L, Ianora AAS, Angelelli G. Abbreviated combined MR protocol: a new faster strategy for characterizing breast lesions. Clinical breast cancer. 2016;16(3):207-211.

16. Kuhl CK, Mielcareck P, Klaschik S, Leutner C, Wardelmann E, Gieseke J, et al. Dynamic breast MR imaging: are signal intensity time course data useful for differential diagnosis of enhancing lesions? Radiology. 1999;211(1):101-110.

17. Boetes C, Barentsz JO, Mus RD, Van Der Sluis RF, van Erning LJ, Hendriks JH, et al. MR characterization of suspicious breast lesions with a gadolinium-enhanced TurboFLASH subtraction technique. Radiology. 1994;193(3):777-781.

18. Sardanelli F, Rescinito G, Giordano GD, Calabrese M, Parodi RC. MR dynamic enhancement of breast lesions: high temporal resolution during the first-minute versus eight-minute study. J Comput Assist Tomogr. 2000 0ct;24(5):724-31.

19. Kuhl CK, Schild HH, Morakkabati N. Dynamic bilateral contrast-enhanced MR imaging of the breast: trade-off between spatial and temporal resolution. Radiology. 2005;236(3):789-800.

20. Thomassin-Naggara I, Bazot M, Daraï E, Callard P, Thomassin J, Cuenod CA. Epithelial Ovarian Tumors: Value of Dynamic Contrast-enhanced MR Imaging and Correlation with Tumor Angiogenesis. Radiology. 2008 Jul 1;248(1):148-59.

21. Thomassin-Naggara I, Daraï E, Cuenod CA, Rouzier R, Callard P, Bazot M. Dynamic contrast-enhanced magnetic resonance imaging: A useful tool for characterizing ovarian epithelial tumors. Journal of Magnetic Resonance Imaging. 28(1):111-20.

22. DeLong ER, DeLong DM, Clarke-Pearson DL. Comparing the areas under two or more correlated receiver operating characteristic curves: a nonparametric approach. Biometrics. 1988;837-845.

23. Tuncbilek N, Tokatli F, Altaner S, Sezer A, Türe M, Omurlu IK, et al. Prognostic value DCE-MRI parameters in predicting factor disease free survival and overall survival for breast cancer patients. European journal of radiology. 2012;81(5):863-867.

24. Hawighorst H, Weikel W, Knapstein PG, Knopp MV, Zuna I, Schönberg SO, et al. Angiogenic activity of cervical carcinoma: assessment by functional magnetic resonance imaging-based parameters and a histomorphological approach in correlation with disease outcome. Clinical cancer research. 1998;4(10):2305-2312.

25. Buadu LD, Murakami J, Murayama S, Hashiguchi N, Sakai S, Masuda K, et al. Breast lesions: correlation of contrast medium enhancement patterns on MR images with histopathologic findings and tumor angiogenesis. Radiology. 1996;200(3):639-649. 26. Trecate G, Tess JDT, Vergnaghi D, Bergonzi S, Mariani G, Ferraris C, et al. Lobular breast cancer: how useful is breast magnetic resonance imaging? Tumori Journal. 2001;87(4):232-238.

27. Sittek H, Perlet C, Untch M, Kessler M, Reiser M. Dynamic MR-mammography in invasive lobular breast cancer. Rontgenpraxis; Zeitschrift fur radiologische Technik. 1998;51(7):235-242.

28. TRICKS / TWIST [Internet]. Questions and Answers in MRI. [cited 2018 Mar 15]. Available from: http://mriquestions.com/tricks-or-twist.html 
TABLES

Table 1: Definitive excision histology results

\begin{tabular}{lll}
\hline Benign & 27 adenosis / sclerosing adenosis \\
$\mathbf{3 8 . 5 \%}$ & 13 papillomas \\
& 11 fibroadenomas \\
& 4 & fibrosis \\
& 3 & cyst \\
& 2 & usual ductal hyperplasia \\
& 2 & abscess \\
& 2 & granulomatous mastitis \\
& 2 & ductal inflammation \\
& 3 & others (tubular adenoma, fat necrosis, benign lymph node) \\
\hline At-risk & 3 & LCIS \\
$\mathbf{4 \%}$ & 2 & radial scar \\
& 1 & ADH \\
& 1 & ALH \\
\hline Malignant & 18 & DCIS \\
$\mathbf{5 7 . 5 \%}$ & 58 & IDC \\
& 18 & ILC \\
& 3 & invasive papillary carcinoma \\
& 6 & others (including one metastasis)
\end{tabular}

LCIS: Lobular Carcinoma In Situ; ADH: Atypical Ductal Hyperplasia; ALH: Aypical Lobular Hyperplasia; DCIS: Ductal Carcinoma In Situ; IDC: Invasive Ductal Carcinoma; ILC: Invasive Lobular Carcinoma; 
Table 2: Morphological analysis for masses and NME (Non-Mass Enhancement) on the FULL protocol with Kappa correlation to the FAST protocol. Morphological criteria were dichotomized as suspicious or non-suspicious. For mass: an irregular shape, irregular or speculated margins, heterogeneous or rim enhancement were considered as suspicious. For NME: linear and segmental enhancement pattern, clumped or cluster ring internal enhancement characterstics were considered as suspicious.

\begin{tabular}{|c|c|c|c|c|c|c|}
\hline $\operatorname{Mass}(n=125)$ & & $\begin{array}{l}\text { Malignant } \\
(n=103)\end{array}$ & $\begin{array}{l}\text { Benign } \\
(n=74)\end{array}$ & $\begin{array}{l}P \\
\text { (Fischer) }\end{array}$ & $\begin{array}{l}\text { OR } \\
\text { (CI 95\%) }\end{array}$ & $\begin{array}{l}\text { Kappa } \\
\text { between } \\
\text { DCE and } \\
\text { HTR-DCE } \\
\text { (CI 95\%) }\end{array}$ \\
\hline \multirow[t]{2}{*}{ Shape } & $\begin{array}{l}\text { Non-suspicious } \\
38 / 125\end{array}$ & $\begin{array}{l}12 / 38 \\
(32 \%)\end{array}$ & $\begin{array}{l}26 / 38 \\
(68 \%)\end{array}$ & \multirow[b]{2}{*}{$\mathrm{p}<0.001$} & \multirow{2}{*}{$\begin{array}{l}7.7 \\
(3.3-18.2)\end{array}$} & \multirow{2}{*}{$\begin{array}{l}0.70 \\
(0.58-0.80)\end{array}$} \\
\hline & $\begin{array}{l}\text { Suspicious* } \\
87 / 125\end{array}$ & $\begin{array}{l}68 / 87 \\
(78 \%)\end{array}$ & $\begin{array}{l}19 / 87 \\
(22 \%)\end{array}$ & & & \\
\hline \multirow[t]{2}{*}{ Margin } & $\begin{array}{l}\text { Non-suspicious } \\
32 / 125\end{array}$ & $\begin{array}{l}9 / 32 \\
(28 \%)\end{array}$ & $\begin{array}{l}23 / 32 \\
(72 \%)\end{array}$ & \multirow[b]{2}{*}{$<0.0001$} & \multirow[t]{2}{*}{$\begin{array}{l}8.2 \\
(3.3-20.4)\end{array}$} & \multirow[t]{2}{*}{$\begin{array}{l}0.80 \\
(0.72-0.88)\end{array}$} \\
\hline & $\begin{array}{l}\text { Suspicious** } \\
93 / 125\end{array}$ & $\begin{array}{l}71 / 93 \\
(76 \%)\end{array}$ & $\begin{array}{l}22 / 93 \\
(24 \%)\end{array}$ & & & \\
\hline \multirow[t]{2}{*}{$\begin{array}{l}\text { Type of } \\
\text { enhancement }\end{array}$} & $\begin{array}{l}\text { Non-suspicious } \\
47 / 125(38 \%)\end{array}$ & $\begin{array}{l}20 / 47 \\
(43 \%)\end{array}$ & $\begin{array}{l}27 / 47 \\
(57 \%)\end{array}$ & \multirow[b]{2}{*}{0.002} & \multirow[t]{2}{*}{$\begin{array}{l}4.4 \\
(1.9-10.6)\end{array}$} & \multirow[t]{2}{*}{$\begin{array}{l}0.57 \\
(0.46-0.69)\end{array}$} \\
\hline & $\begin{array}{l}\text { Suspicious*** } \\
78 / 125(62 \%)\end{array}$ & $\begin{array}{l}60 / 78 \\
(77 \%)\end{array}$ & $\begin{array}{l}18 / 78 \\
(23 \%)\end{array}$ & & & \\
\hline $\begin{array}{l}\text { Time intensity } \\
\text { curve }\end{array}$ & Type 3 & $\begin{array}{l}38 / 53 \\
(72 \%)\end{array}$ & $\begin{array}{l}15 / 53 \\
(28 \%)\end{array}$ & 0.25 & - & - \\
\hline \multicolumn{7}{|l|}{ NME (n=49) } \\
\hline \multirow[t]{2}{*}{$\begin{array}{l}\text { Enhancement } \\
\text { pattern }\end{array}$} & $\begin{array}{l}\text { Non-suspicious } \\
20 / 48(42 \%)\end{array}$ & $8 / 20(40 \%)$ & $\begin{array}{l}12 / 20 \\
(60 \%)\end{array}$ & \multirow[t]{2}{*}{0.35} & $\begin{array}{l}1.73 \\
(0.54- \\
5.54)\end{array}$ & $\begin{array}{l}0.63 \\
(0.49-0.77)\end{array}$ \\
\hline & $\begin{array}{l}\text { Suspicious } * * * * \\
28 / 48(58 \%)\end{array}$ & $\begin{array}{l}15 / 28 \\
(54 \%)\end{array}$ & $\begin{array}{l}13 / 28 \\
(46 \%)\end{array}$ & & & \\
\hline \multirow{2}{*}{$\begin{array}{l}\text { Internal } \\
\text { enhancement } \\
\text { characteristics }\end{array}$} & $\begin{array}{l}\text { Non-suspicious } \\
30 / 48(62.5 \%)\end{array}$ & $\begin{array}{l}10 / 30 \\
(33 \%)\end{array}$ & $\begin{array}{l}20 / 30 \\
(67 \%)\end{array}$ & \multirow[t]{2}{*}{0.0116} & $\begin{array}{l}5.2(1.44- \\
18.71)\end{array}$ & $\begin{array}{l}0.95 \\
(0.94-0.96)\end{array}$ \\
\hline & $\begin{array}{l}\text { Suspicious****** } \\
18 / 48(37.5 \%)\end{array}$ & $\begin{array}{l}13 / 18 \\
(72 \%)\end{array}$ & $\begin{array}{l}5 / 18 \\
(28 \%)\end{array}$ & & - & - \\
\hline
\end{tabular}

\footnotetext{
* irregular

** irregular, spiculated

*** heterogeneous, rim enhancement

**** linear, segmental

***** clumped, clustered ring
} 
Table 3: Evaluation of the clinical of malignancy for each BI-RADS classification for the different protocols tested

\begin{tabular}{|c|c|c|c|}
\hline PPV /LR+ & FULL & FAST & ABBREVIATED \\
\hline \multirow[t]{2}{*}{ BI-RADS 3} & $18.7 \%(3 / 16)$ & $27.6 \%(8 / 29)$ & $12.8 \%(5 / 39)$ \\
\hline & $\mathbf{0 . 1 7}(0.05-0.58)$ & $\mathbf{0 . 2 8}(0.13-0.60)$ & $\mathbf{0 . 1 1}(0.04-0.26)$ \\
\hline \multirow[t]{2}{*}{ BI-RADS 4a } & $21.2 \%(7 / 33)$ & $18.2 \%(4 / 22)$ & $41.7 \%(10 / 24)$ \\
\hline & $\mathbf{0 . 2 0}(0.09-0.43)$ & $\mathbf{0 . 1 6}(0.06-0.46)$ & $\mathbf{0 . 5 3}(0.25-1.12)$ \\
\hline \multirow[t]{2}{*}{ BI-RADS 4b } & $\mathbf{3 7 . 5 \%}(12 / 32)$ & 41.4\% (12/29) & $52.9 \%(9 / 17)$ \\
\hline & $\mathbf{0 . 4 4}(0.23-0.85)$ & $\mathbf{0 . 5 2}(0.26-1.02)$ & $\mathbf{0 . 8 3}(0.34-2.05)$ \\
\hline \multirow[t]{2}{*}{ BI-RADS 4c } & 69.8\% (30/43) & 66.7\% (30/45) & $66.7 \%(30 / 45)$ \\
\hline & $\mathbf{1 . 7 0}(0.95-3.04)$ & $\mathbf{1 . 4 8}(0.86-2.54)$ & $1.48(0.86-2.54)$ \\
\hline \multirow[t]{2}{*}{ BI-RADS 5} & $92.7 \%(51 / 55)$ & $90.7 \%(49 / 54)$ & $90.7 \%(49 / 54)$ \\
\hline & $\mathbf{9 . 4 1}(3.55-24.91)$ & $\mathbf{7 . 2 3}(3.03-17.28)$ & $\mathbf{7 . 2 3}_{(3.03-17.28)}$ \\
\hline
\end{tabular}


Table 4: Semi-quantitative parameter analysis for whole-lesion (WL) and hot-spot ROI (HS)

\begin{tabular}{|c|c|c|c|c|c|c|}
\hline & & Benign $(n=76)$ & Malignant $(n=103)$ & $P(M W)$ & $A U C$ & $\begin{array}{c}P(\text { difference } \\
\text { between } \\
A U C)\end{array}$ \\
\hline EI & $\begin{array}{l}\text { WL } \\
\text { HS }\end{array}$ & $\begin{array}{c}\mathbf{5 2 9 7} \\
(3385-8246) \\
\mathbf{8 4 0 9} \\
(5759-13491)\end{array}$ & $\begin{array}{c}\mathbf{8 4 6 4} \\
(6142-11006) \\
\mathbf{1 2 6 1 8} \\
(8634-15683)\end{array}$ & $\begin{array}{l}<0.0001 \\
0.0004\end{array}$ & $\begin{array}{l}0.687 \\
0.655\end{array}$ & 0.1628 \\
\hline EA & $\begin{array}{l}\text { WL } \\
\text { HS }\end{array}$ & $\begin{array}{c}\mathbf{1 2 3 . 9} \\
(86.9-169.0) \\
\mathbf{1 7 7} \\
(129-251) \\
\end{array}$ & $\begin{array}{c}\mathbf{1 5 5 . 4} \\
(118.7-190.8) \\
\mathbf{2 1 8} \\
(171-285)\end{array}$ & $\begin{array}{l}0.0007 \\
0.0056\end{array}$ & $\begin{array}{l}0.648 \\
0.622\end{array}$ & 0.550 \\
\hline THR & $\begin{array}{l}\text { WL } \\
\text { HS }\end{array}$ & $\begin{array}{c}\mathbf{4 5 . 2} \\
(39.2-51.2) \\
\mathbf{4 3} \\
(38.3-48.4)\end{array}$ & $\begin{array}{c}\mathbf{3 8 . 6} \\
(32.8-43.4) \\
\mathbf{3 5} \\
(31-41.9) \\
\end{array}$ & $\begin{array}{l}0.0001 \\
0.0002\end{array}$ & $\begin{array}{l}0.712 \\
0.682\end{array}$ & 0.190 \\
\hline Maximal Slope & $\begin{array}{l}\text { WL } \\
\text { HS }\end{array}$ & $\begin{array}{c}\mathbf{3 . 4 0} \\
(2.39-4.93) \\
\mathbf{5 . 0 9} \\
(3.82-7.74)\end{array}$ & $\begin{array}{c}\mathbf{4 . 6 4} \\
(3.25-6.84) \\
\mathbf{6 . 5 1} \\
(4.71-10.13)\end{array}$ & $\begin{array}{l}0.0006 \\
0.0113\end{array}$ & $\begin{array}{l}0.650 \\
0.612\end{array}$ & 0.0963 \\
\hline MSI & $\begin{array}{l}\text { WL } \\
\text { HS }\end{array}$ & $\begin{array}{c}\mathbf{4 . 1 3} \\
(2.70-5.81) \\
\mathbf{6 . 5 2} \\
(4.27-9.10)\end{array}$ & $\begin{array}{c}\mathbf{5 . 9 6} \\
(4.61-9.25) \\
\mathbf{8 . 2 4} \\
(6.03-12.22)\end{array}$ & $\begin{array}{l}0.0001 \\
0.0025\end{array}$ & $\begin{array}{l}0.695 \\
0.633\end{array}$ & 0.0116 \\
\hline WIR & $\begin{array}{l}\text { WL } \\
\text { HS }\end{array}$ & $\begin{array}{c}\mathbf{1 . 3 2} \\
(0.92-1.60) \\
\mathbf{1 . 8 6} \\
(1.47-2.60)\end{array}$ & $\begin{array}{c}\mathbf{1 . 7} \\
(1.30-2.14) \\
\mathbf{2 . 4 3} \\
(1.77-3.55)\end{array}$ & $\begin{array}{l}0.0001 \\
0.0014\end{array}$ & $\begin{array}{l}0.671 \\
0.641\end{array}$ & 0.4260 \\
\hline R Max & $\begin{array}{l}\text { WL } \\
\text { HS }\end{array}$ & $\begin{array}{c}\mathbf{1 2 3} \\
(85.4-118.3) \\
\mathbf{1 7 4} \\
(134-234)\end{array}$ & $\begin{array}{c}\mathbf{1 5 7 . 3} \\
(118.3-191.5) \\
\mathbf{2 1 8} \\
(162-282)\end{array}$ & $\begin{array}{l}0.0002 \\
0.0059\end{array}$ & $\begin{array}{l}0.664 \\
0.621\end{array}$ & 0.170 \\
\hline Rmax timing & $\begin{array}{l}\text { WL } \\
\text { HS }\end{array}$ & $\begin{array}{c}\mathbf{9 3 . 8} \\
(87.1-100.4) \\
\mathbf{9 2 . 6} \\
(87.1-100.4)\end{array}$ & $\begin{array}{c}\mathbf{9 3 . 8} \\
(87.1-100.4) \\
\mathbf{8 7 . 1} \\
(79.4-100.4)\end{array}$ & $\begin{array}{l}0.149 \\
0.122\end{array}$ & - & - \\
\hline
\end{tabular}

Semi-quantitative parameters were expressed as median and interquartile 25-75 for each hot spot $(n=177)$ or whole-lesion ROI (n=179)i.e. 2 lesions were so small that the hot spot was superposed with the whole lesionROI EI: Enhancement Integral; EA: Enhancement Amplitude; THR: Time of Half Rising; MSI: Maximal Slope of Increase; WIR: Wash In Rate; $R$ max: Maximal enhancement Rate; Rmax timing: time relative to maximal enhancement rate.

Table 5: Lesion Heterogeneity (standard deviation of pixel intensity whithin the Wholelesion ROI) evaluated on AUROCSTD at each rank of the HTR-DCE sequence

\begin{tabular}{|l|c|c|c|c|c|}
\hline & AUC ROC & $\begin{array}{c}\text { THRES } \\
\text { HOLD }\end{array}$ & SE & SP & $P$ \\
\hline STD RANK 3 & 0.674 & $>58.3$ & 90.3 & 39.5 & $<0.0001$ \\
\hline STD RANK 5 & 0.730 & $>84.1$ & 83.5 & 51.3 & $<0.0001$ \\
\hline STD RANK 7 & 0.689 & $>136.7$ & 57.3 & 73.7 & $<0.0001$ \\
\hline STD RANK 9 & 0.666 & $>106.2$ & 84.5 & 44.7 & $<0.0001$ \\
\hline
\end{tabular}


Table 6: Comparison of diagnostic performance of semi-quantitative parameters

\begin{tabular}{lccccc} 
& AUC ROC & Threshold & Sensitivity & Specificity & p \\
\hline EI & 0.693 & $>5495$ & 81.55 & 53.95 & $<0.0001$ \\
EA & 0.648 & $>139$ & 66.02 & 64.47 & 0.0005 \\
THR & 0.712 & $\delta 42 \mathrm{~s}$ & 69.9 & 68.4 & $<0.001$ \\
MSI & 0.702 & $>4.42$ & 79.61 & 57.89 & $<0.0001$ \\
WIR & 0.671 & $>1.6$ & 58.3 & 76.3 & $<0.0001$
\end{tabular}

Threholds determined to allow a better compromise between sensitivity and specificity using ROC curves.

Table 7: Comparison of diagnostic performance of the different reading protocols

\begin{tabular}{llll} 
& FULL & FAST & FAST + HTR-DCE \\
\hline Performance & & & \\
$\quad$ True-positive result, $n$ & 100 & 95 & 98 \\
$\quad$ False-negative result, $n$ & 3 & 8 & 5 \\
$\quad$ True-negative result, $n$ & 13 & 21 & 34 \\
$\quad$ False-positive result, $n$ & 63 & 55 & 42 \\
Sensitivity (95\% CI) & $0.97(0.93-1)$ & $0.92(0.87-0.97)$ & $0.95(0.91-0.99)$ \\
Specificity (95\% CI) & $0.17(0.89-0.93)$ & $0.27(0.17-0.37)$ & $0.45(0.33-0.56)$ \\
Positive likelihood ratio (95\% CI) & $1.17(1.05-1.30)$ & $1.27(1.10-1.48)$ & $1.72(1.40-2.12)$ \\
Negative likelihood ratio (95\% CI) & $1.17(0.05-0.58)$ & $0.28(0.13-0.60)$ & $0.11(0.04-0.26)$ \\
Positive predictive value (95\% CI) & 0.61 & 0.63 & 0.70 \\
Negative predictive value (95\% CI) & 0.81 & 0.72 & 0.87 \\
Accuracy (95\% CI) & 0.63 & 0.65 & 0.73
\end{tabular}


Figure 1: Flow Chart

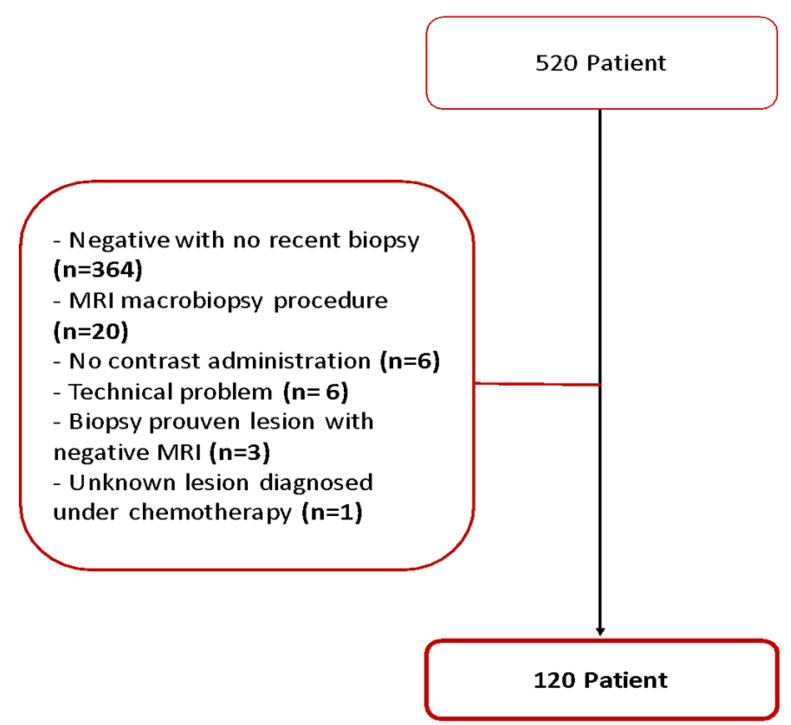

Figure 2: MR acquisition and reading protocol

\section{Acquisition protocol}

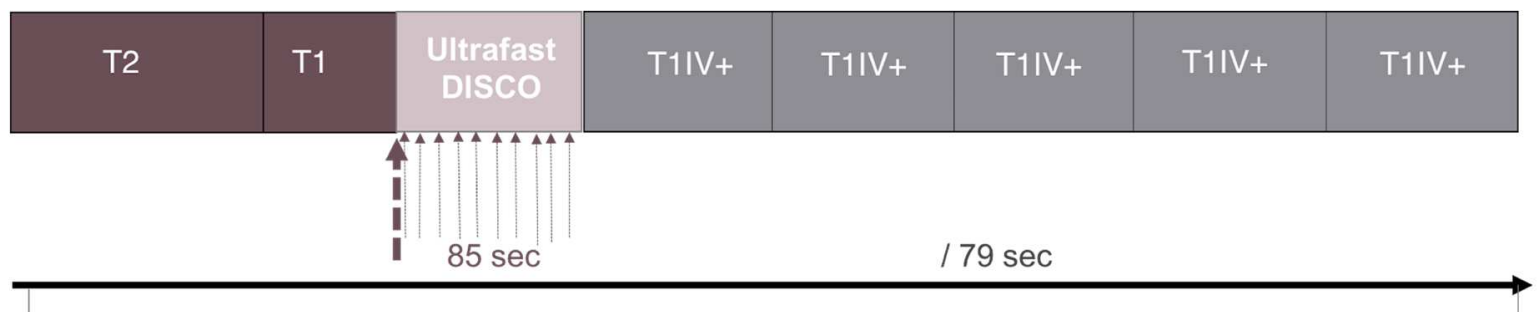

\section{Reading protocols}

1) FULL protocol: composed of all sequences acquired except HTR-DCE sequence

2) FAST protocol: composed of $\mathrm{T} 2 \mathrm{~W}$, high spatial $\mathrm{T} 1 \mathrm{~W}$ acquisition before and after contrast administration

3) ABBREVIATED protocol: Adding an HTR-DCE (= DISCO) sequence to FAST protocol

1)

2)

3) 
Figure 3: Semiquantitative parameters

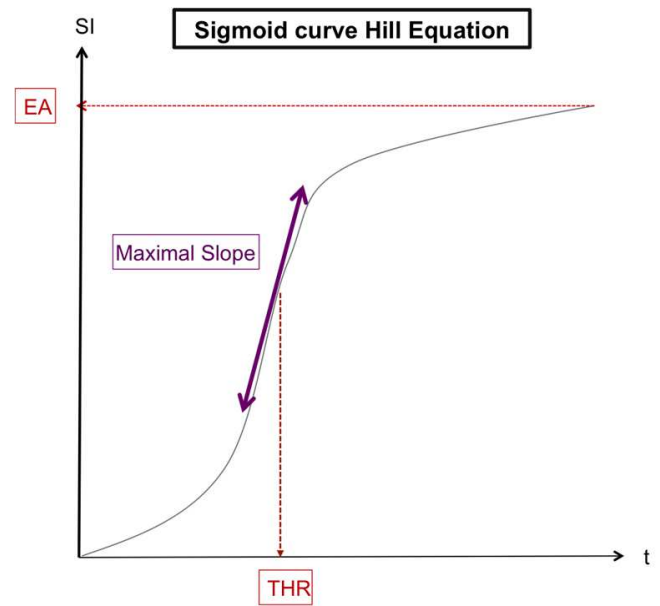

a) EI: Enhancement Integral; EA: Enhancement Amplitude; THR: Time of Half Rising; MSI: Maximal Slope of Increase; WIR: Wash In Rate;

b) Semi-quatitative parameters dervied from the Hill Equation

Figure 4: Comparison between benign and malignant lesions related to the first rank of visbility. Most malignant lesions enhance early within the first four ranks (Time to Enhancement $<31$ s), whereas benignant lesions have a more normal low distribution.

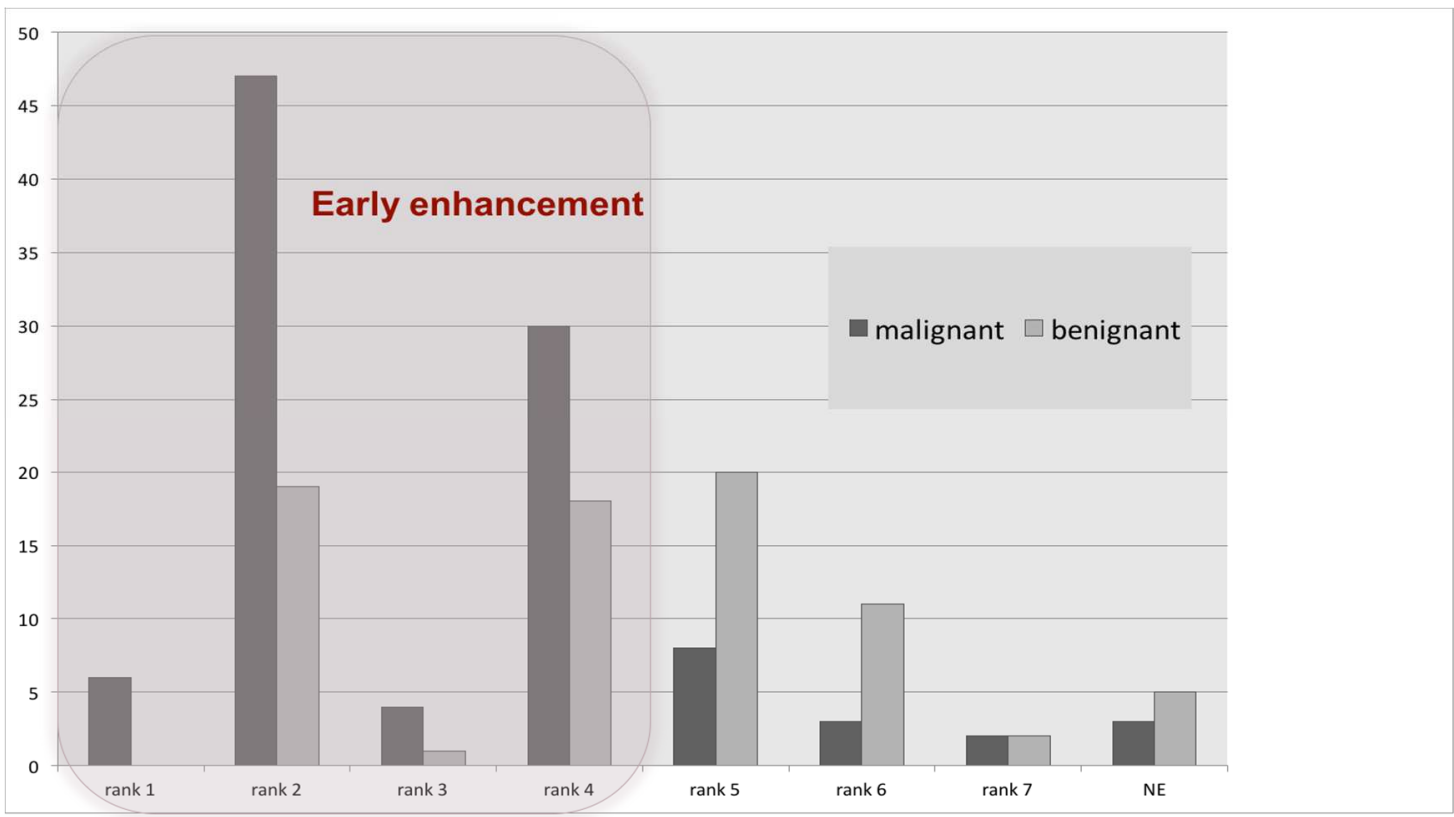

NE: non-enhanced lesion 
Figure 5: Correlation between lesion size and TTE

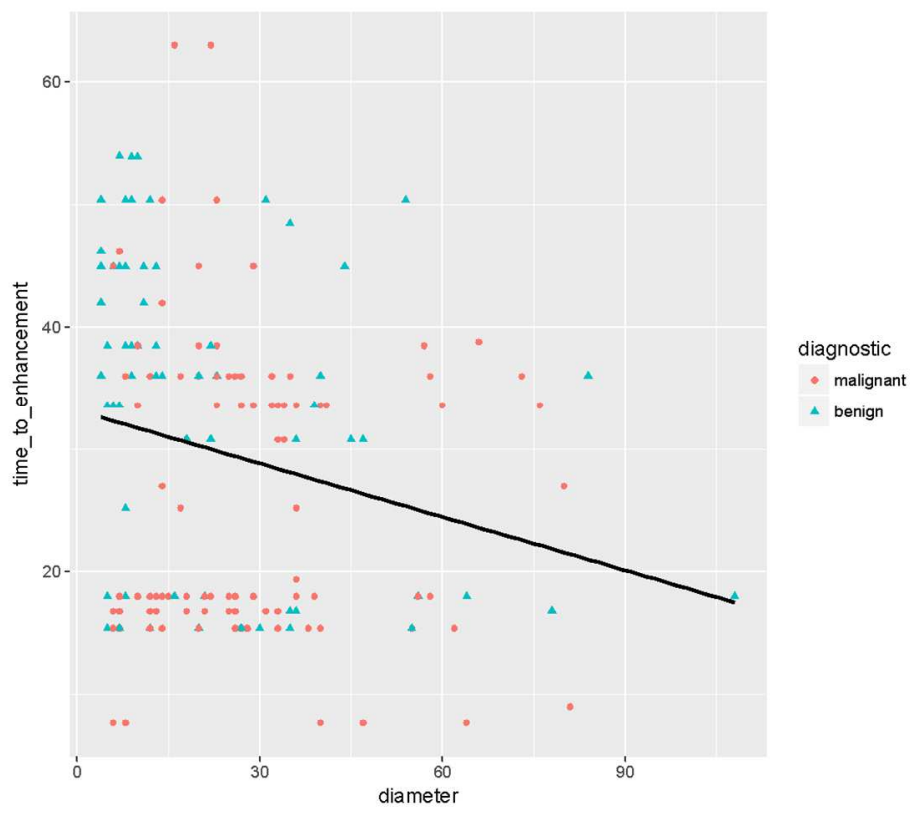

Figure 6: Integration of HTR-DCE sequence; TTE <31 s (early enhancement) to FAST protocol
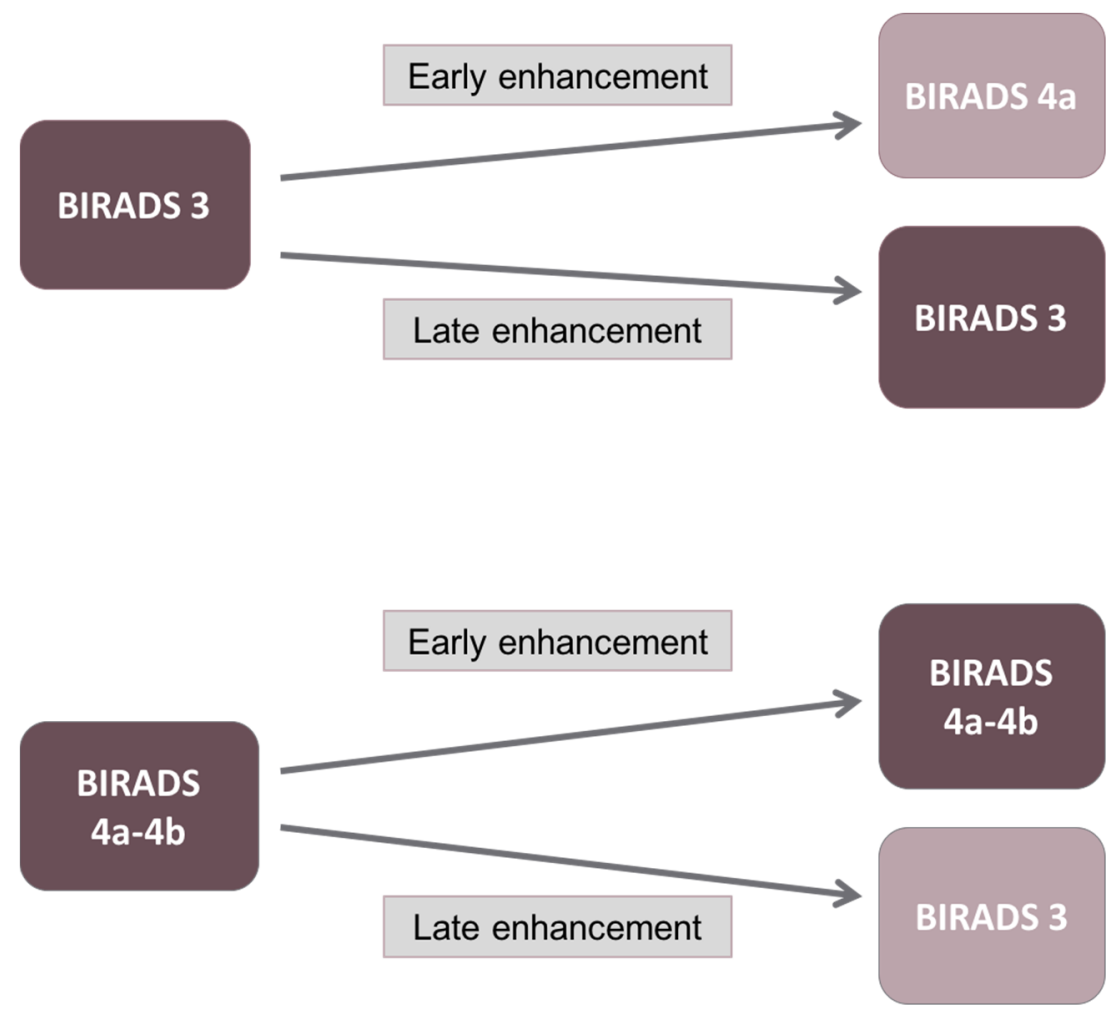
Figure 7: Percentage of malignant lesions in the new BI-RADS classification with the abbreviated protocol (combining FAST protocol and HTR-DCE sequence) compared to FAST protocol alone and FULL protocol

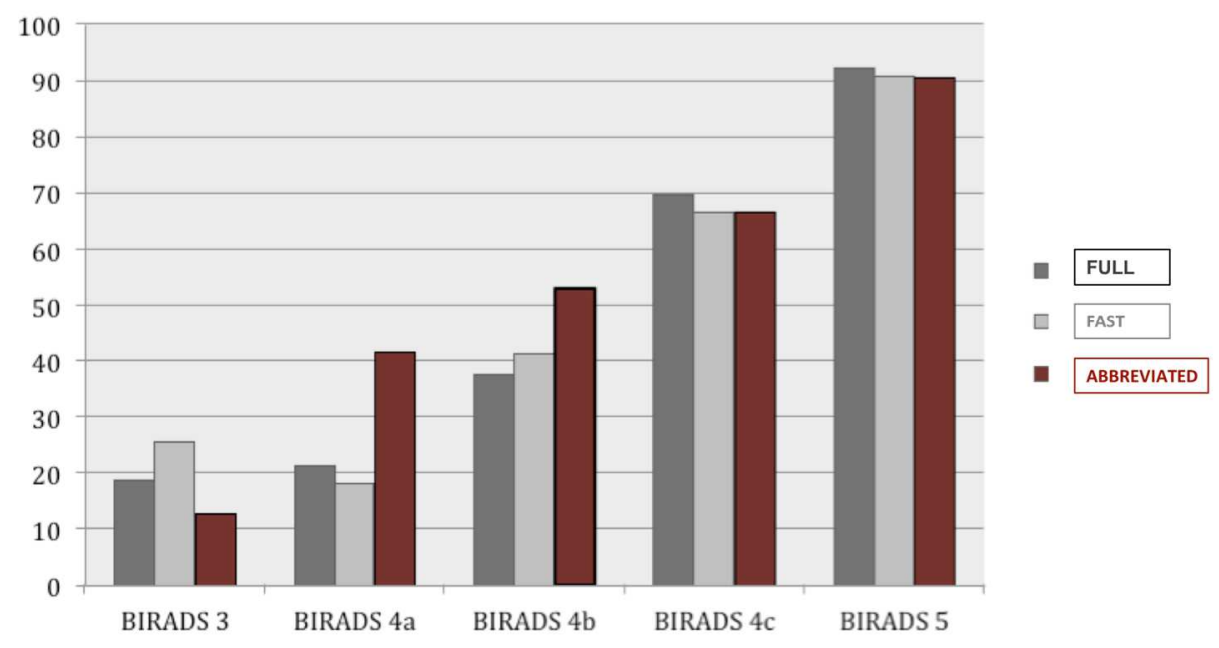


Figure 8: A 42 YO high-risk woman referred for breast cancer screanning. Vibrant and Disco focal enhancement that corresponds to a mass, enhancing according a Time intensity curve type 2. According to FULL protocol, this lesion was rated Bi-rads 3. According to FAST protocol, missing dynamic criteria, the lesion would be rated either BI-RADS 3 or 4a. Adding HTR-DCE sequence TTE criteria (lesion visible before $31 \mathrm{~s}$ (before rank 4), this lesion was classified as BI-RADS 4a. A second look by ultrasonography allowed to perform a percutaneous biopsy that reveled an invasive lobular carcinoma.

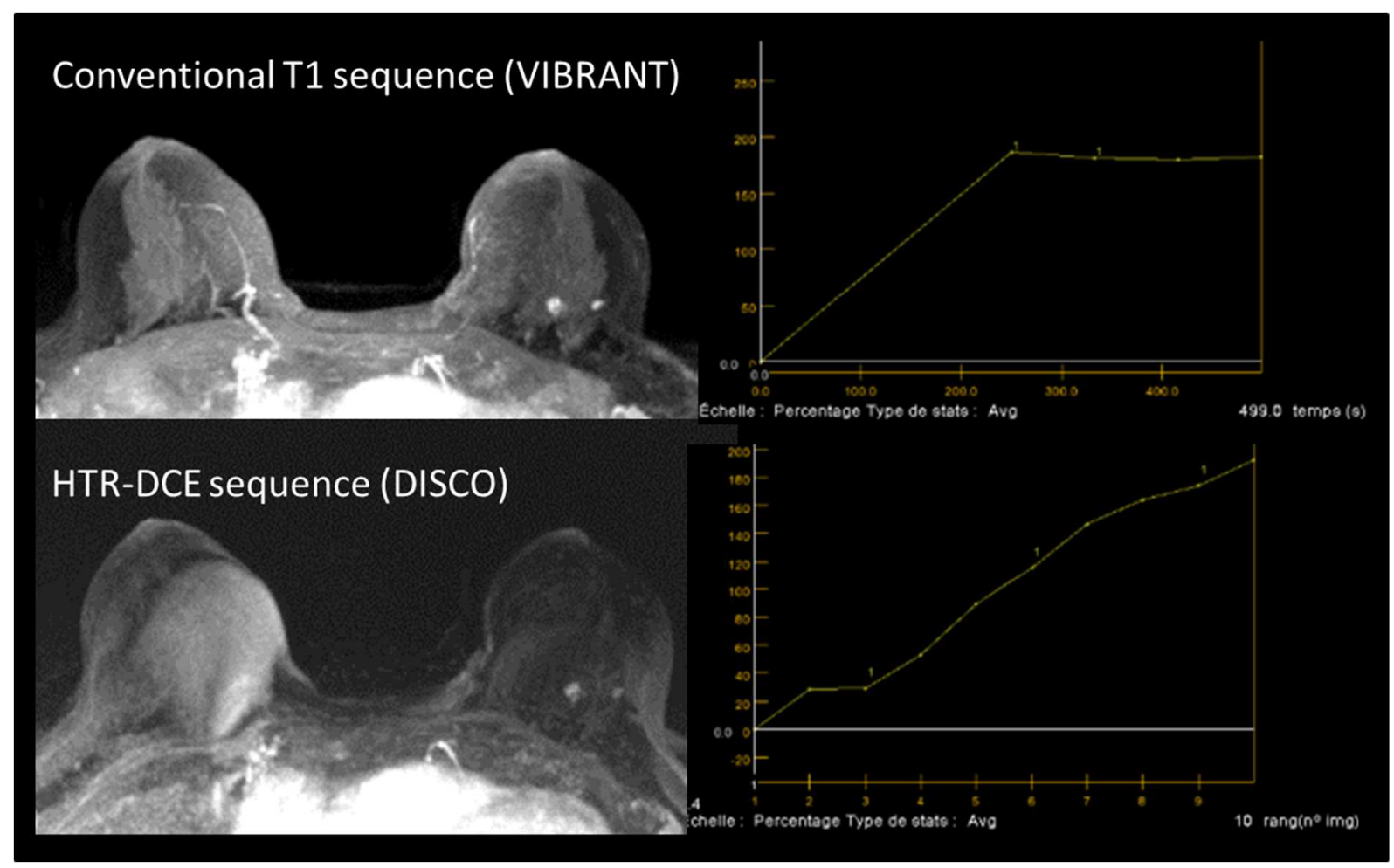




\section{Supplemental material 1: Parameters of MRI sequences}

\begin{tabular}{|c|c|c|c|c|}
\hline & $\begin{array}{l}\text { Axial T2 } \\
\text { FSE }\end{array}$ & $\begin{array}{l}\text { Axial T1 EG } \\
\text { VIBRANT }\end{array}$ & $\begin{array}{l}\text { Axial T1 EG } \\
\text { DISCO Flex }\end{array}$ & $\begin{array}{l}\text { Sagittal T1 EG } \\
\text { VIBRANT }\end{array}$ \\
\hline $\begin{array}{l}\text { TE } \\
\text { TR }\end{array}$ & $\begin{array}{l}\text { TE: } 102 \\
\text { TR: } 9789\end{array}$ & $\begin{array}{c}\text { TE1 : } 2.2 \text { / TE2 }: 4.7 \\
\text { TR: } 7.1\end{array}$ & $\begin{array}{c}\text { TE1 : } 2.2 \text { / TE2 }: \\
4.5 \\
\text { TR: } 6.3\end{array}$ & $\begin{array}{l}\text { TE1: } 2.2 \\
\text { TE2: } 4.9 \\
\text { TR: } 7.4\end{array}$ \\
\hline Flip angle $^{\circ}$ & - & 10 & 15 & 12 \\
\hline Matrix & $416 \times 320$ & $360 \times 360$ & $288 \times 128$ & $288 \times 256$ \\
\hline Slice thickness (mm) & 2 & 2 & 2 & 2 \\
\hline $\begin{array}{l}\text { FOV }(\mathrm{mm}) \\
\text { Phase FOV }\end{array}$ & 350 & 350 & 350 & 240 \\
\hline Nex & 1 & 1 & 1 & 1 \\
\hline BW (Hz) & 35.71 & 83.33 & 125 & 62.5 \\
\hline $\begin{array}{l}\text { ETL (echo-train } \\
\text { length) }\end{array}$ & 25 & NA & NA & NA \\
\hline $\begin{array}{l}\text { Parallel imaging } \\
\text { factor }\end{array}$ & ASSETy 2 & ACRy 2 & ARCy 3 & $\mathrm{ARCz} 2,5$ \\
\hline $\begin{array}{l}\text { Spatial resolution: } \\
(\mathrm{mm})\end{array}$ & $\begin{array}{c}0.84 \times 1.09 \\
\times 2 \\
\end{array}$ & $0.97 \times 0.97 \times 2$ & $1.22 \times 2.73 \times 2$ & $0.83 \times 0.94 \times 2$ \\
\hline Reordering & linear & Eliptical centric & NA & Linear \\
\hline Central Zone (\%) & NA & NA & $16 \%$ & NA \\
\hline $\begin{array}{l}\text { Sampling Density } \\
\text { Outer Zone }\end{array}$ & NA & NA & $30 \%$ & NA \\
\hline Fat-suppresion & None & Flex & Flex & Flex \\
\hline $\begin{array}{l}\text { Temporal resolution } \\
\text { (s) }\end{array}$ & NA & $1 \min 19$ & $7.7 \mathrm{sec}$ & NA \\
\hline N. of dynamics & 1 & 4 & 11 & 1 \\
\hline $\begin{array}{l}\text { Acquisition time } \\
\text { (min) }\end{array}$ & $2 \min 57 \mathrm{~s}$ & $5 \min 21 \mathrm{~s}$ & $1 \mathrm{~min} 18 \mathrm{~s}$ & $2 \min 7 \mathrm{sec}$ \\
\hline
\end{tabular}

ASSET, Array Spatial Sensitivity Encoding Technique; ARC, Autocalibrating Reconstruction for Cartesian Imaging; VIBRANT, Volume Imaging for Breast AssesmeNT; BW, BandWidth; FOV, Field Of View; TE, Time of Echo; TR, Time of Repetition; Nex, Number of Excitation 
Supplemental material 2: BI-RADS classification on FAST protocol (regardless of Time intensity curve).

Mass:

- BI-RADS 3: benign morphology and homogeneous enhancement

- BI-RADS 4a: benign morphology but heterogeous enhancement

- BI-RADS 4b: irregular shape or irregular margins

- BI-RADS 4c: irregular shape and irregular margins

- BI-RADS 5: irregular shape with spiculated margins or necrotic part

Non mass like enhancement (NME)

- BI-RADS 3: focal and homogeneous and size $<10 \mathrm{~mm}$

- BI-RADS 4a: regional or focal and homogeneous and size $>10 \mathrm{~mm}$

- BI-RADS 4b: linear and homogeneous / regional or focal and heterogeneous

- BI-RADS 4c: linear and heterogeneous / regional or focal and cluster ring or clumped enhancement

- BI-RADS 5: segmental whatever the enhancement characteristics / linear and clusterring enhancement.

Focus were ranked BI-RADS 3

References:

(1) Giess, Radiographics, 2013

(2) Baltzer, Am J Roentgenol., 2010

(3) Gutierrez, Am J Roentgenol. 2009

(4) Thomassin-Naggara, Radiology, 2011

1. Giess CS, Raza S, Birdwell RL. Patterns of Nonmasslike Enhancement at Screening Breast MR Imaging of High-Risk Premenopausal Women. RadioGraphics. 2013 Aug 30;33(5):1343-60.

2. Baltzer PA, Benndorf M, Dietzel M, Gajda M, Runnebaum IB, Kaiser WA. False-positive findings at contrast-enhanced breast MRI: a BI-RADS descriptor study. American Journal of Roentgenology.

2010;194(6):1658-1663.

3. Gutierrez RL, DeMartini WB, Eby PR, Kurland BF, Peacock S, Lehman CD. BI-RADS lesion characteristics predict likelihood of malignancy in breast MRI for masses but not for nonmasslike enhancement. American Journal of Roentgenology. 2009;193(4):994-1000.

4. Thomassin-Naggara I, Trop I, Chopier J, David J, Lalonde L, Darai E, et al. Nonmasslike enhancement at breast MR imaging: the added value of mammography and US for lesion categorization. Radiology.

2011;261(1):69-79. 